\title{
Multiple Linear Regression Model-Based Old People Sports Leisure Behavior Research under Urbanization Background
}

\author{
Ping Dai ${ }^{*}$
}

Department of Physical Education, Jiangnan University, Wuxi 214122, Jiangsu, China

\begin{abstract}
Presently population aging issue becomes increasingly serious, old people occupy more and more proportions in Chinese population. To some extent, old people living quality represents a country's civil living standards and a country comprehensive strength. The paper utilizes multiple linear regression models to analyze old people sports leisure demands. From six perspectives as old people gender, age, cultural standard, monthly income, income satisfaction, physical health status, it analyzes every perspective relations with pass time, relax, capacity improving, making friends and interaction, exploration of knowledge these five aspects. From obtained function relations, it gets conclusion that old people sports leisure demands have certain relations with old people classification.
\end{abstract}

Keywords: Demands classification, multiple linear regression, old people, sports leisure, urbanization.

\section{INTRODUCTION}

In recent years, with intensifying of population aging problem, people's attention to old people becomes higher and higher. Since 2008 China succeeded in holding Olympic Games, physical exercise consciousness have gone deeply into human's mind, especially for the old, physical exercise, leisure sports have become an indispensible part of their daily life. In the background of urbanization, aging population sports leisure problem is even the focus of relative experts and scholars researches [1].

Zhao Jia-Hua in the article "Xian city old people leisure behavior research", he took Xian city old people as research objects, adopted stratified sampling investigation method to investigate, regarded investigation result as original data, carried on validity and reliability analysis, variance analysis, cross tabulation analysis and T test on it [2]. Made research from the perspective of leisure status, leisure behavior constraint factors and satisfaction and so on, research result showed that old people physical exercise main range was home, community and place of residence nearby within 1000 meters regions [3]. Due to gender, age, characters and other aspects differences, outdoors and domestic leisure exercise time distribution were different, leisure physical exercise hobbies and participation extent were also different. The article pointed out factors that restricted old people leisure sports were various, improving old people leisure living quality needed personal, government and social multiple aspects efforts.

Gao Chun in the article "Chinese cities elderly university leisure education research - take Wuhan city as an example", took Chinese cities elderly university leisure education as research objects. On the basis of layering investigation, made analysis of elderly university students leisure status, the author found that the old leisure motivation levels were lower, leisure way was relative single, scope that could select was narrower, leisure satisfaction was universally lower, causes for above three kinds of problems included the old weak leisure consciousness, lacking of scientific leisure views, short of elder university leisure education [4]. The author highlighted that utilitarianism society indifference, lacking of concerns and recognition on the old leisure education and other problems led to elderly university students lacking of leisure exercises. Li Wen-Chuan in the article "Shanghai city old people sports lifestyle research", selected Shanghai city old people as research objects, comprehensively applied multiple research methods [5]. The author made empirical investigation research on Shanghai city old people leisure life from behavioral agent, behavior base, behavior characteristics, and behavior efficiency four perspectives. Shanghai city old people sports lifestyle showed layering phenomenon, female old people loved comfortable group exercise ways, while male old people preferred to individual event exercise way. Shanghai city old people connected physical exercises with daily activity and lives. Physical exercise gradually replaced traditional fitness, their fitness frequency and fitness time were higher, sports intensity was relative lower, and majored in experience-type physical exercise way [6]. Chen Yue-Lin in the article "Chengdu city downtown old people leisure status and leisure way research", on the basis of analyzing Chengdu city old people traditional life, from leisure motivation, leisure time, leisure type, leisure influence factors and leisure living quality and others multiple perspectives, researched on Chengdu city old people leisure life, research result showed old people participation degree on puzzle type, exchange type, fitness type of activities were higher, but leisure activity contents were single, which affected leisure activities quality [7]. 
Table 1. The old leisure demands distribution.

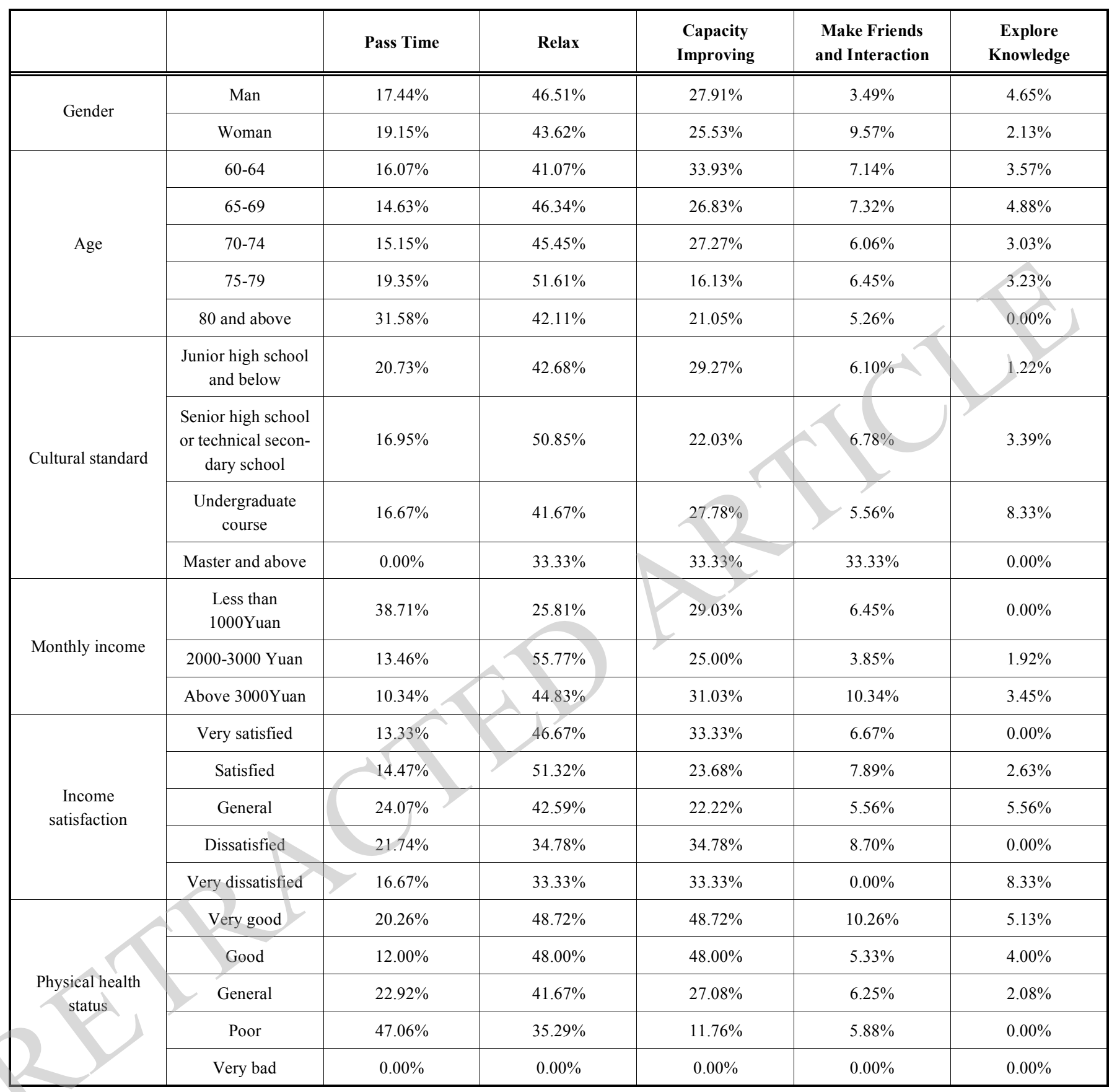

The paper aims to research on different types of old people sports demands problem, old people are classified according to gender, age, cultural standards and others, sports demand will be considered from passing time, relaxing, capacity improving, making friends and interaction as well as exploring knowledge and so on.

\section{DATA PROCESSING AND REGRESSION MODEL INTRODUCTION}

Data collection takes Chengdu city old people as investigation objects, uses layering sampling investigation way, investigation result is as Table 1 shows.
Data is from the article "Chengdu city downtown old people sports leisure status and sports leisure way research".

\subsection{Multiple Linear Regression Models}

Multiple linear regression analysis models are:

$\left\{\begin{array}{l}y=\beta_{0}+\beta_{1} x_{1}+\cdots+\beta_{m} x_{m}+\varepsilon \\ \varepsilon \sim N\left(0, \sigma^{2}\right)\end{array}\right.$

In formula $\beta_{0}, \beta_{1}, \cdots, \beta_{m}, \sigma^{2}$ all are parameters that are uncorrelated to $x_{1}, x_{2}, \cdots, x_{m}$, all are unknown, from which $\beta_{0}, \beta_{1}, \cdots, \beta_{m}$ are regression coefficients. 
Table 2. Gender classification old people demands status table.

\begin{tabular}{|c|c|c|c|c|c|}
\hline Type & Pass Time & Relax & Capacity Improving & $\begin{array}{c}\text { Make Friends and } \\
\text { Interaction }\end{array}$ & Explore Knowledge \\
\hline \hline 1 & 0.1744 & 0.4651 & 0.2791 & 0.349 & 0.465 \\
\hline 2 & 0.1915 & 0.4362 & 0.2553 & 0.957 & 0.213 \\
\hline
\end{tabular}

Table 3. Age classification old people demands status table.

\begin{tabular}{|c|c|c|c|c|c|}
\hline Type & Pass Time & Relax & Capacity Improving & $\begin{array}{c}\text { Make Friends and } \\
\text { Interaction }\end{array}$ & Explore Knowledge \\
\hline \hline 1 & 0.1607 & 0.4107 & 0.3393 & 0.0714 & 0.0357 \\
\hline 2 & 0.1463 & 0.4634 & 0.2683 & 0.0732 & 0.0488 \\
\hline 3 & 0.1515 & 0.4545 & 0.2727 & 0.0606 & 0.06303 \\
\hline 4 & 0.1935 & 0.5161 & 0.1613 & 0.0526 & 0.0323 \\
\hline
\end{tabular}

Now it has $n$ pieces of independent observation data $\left(y_{i}, x_{i 1}, \cdots, x_{i m}\right), i=1, \cdots, n, n>m$, by formula (1), it gets:

$\left\{\begin{array}{l}y_{i}=\beta_{0}+\beta_{1} x_{i 1}+\cdots+\beta_{m} x_{i m}+\varepsilon_{i} \\ \varepsilon_{i} \sim N\left(0, \sigma^{2}\right), i=1, \cdots, n\end{array}\right.$

Record:

$$
\begin{gathered}
X=\left[\begin{array}{cccc}
1 & x_{11} & \cdots & x_{1 m} \\
\vdots & \vdots & \cdots & \vdots \\
1 & x_{n 1} & \cdots & x_{n m}
\end{array}\right], Y=\left[\begin{array}{c}
y_{1} \\
\vdots \\
y_{n}
\end{array}\right] \\
\mathcal{E}=\left[\begin{array}{lll}
\varepsilon_{1} & \cdots & \varepsilon_{n}
\end{array}\right]^{T}, \beta=\left[\begin{array}{llll}
\beta_{0} & \beta_{1} & \cdots & \beta_{m}
\end{array}\right]^{T}
\end{gathered}
$$

Formula (1) can also express as

$$
\left\{\begin{array}{l}
Y=X \beta+\varepsilon \\
\varepsilon \sim N\left(0, \sigma^{2} E_{n}\right)
\end{array}\right.
$$

Among them, $E_{n}$ is $n$ order unit matrix.

Multiple linear regression models are on the basis of lots of data, utilizing regression way to express data that has no rules to have certain function relationship. The model respectively considers gender, age, cultural standard, monthly income, income satisfaction and physical health status classified old people group and passing time, relaxing, capacity improving, making friends and interaction as well as exploring knowledge these five aspects functional relationships.

\subsection{Classification According to Gender}

For Table 1 gender type data, it does processing and gets Table $\mathbf{2}$ data, contents are as Table $\mathbf{2}$ shows. To convenient to make regression, transform percentage into decimals, male is using " 1 " to express, female is using " 2 " to express.
Utilize Matlab to program above multiple linear regression models, by calculating, it gets following results.

$$
\begin{aligned}
& \mathrm{b}=(0.4260,0,0,1.6447,0) \\
& \text { stats }=(1,80.9530,0.0022)
\end{aligned}
$$

By consulting table, it is clear that $\mathrm{R} 2$ is on behalf of decision coefficient( $R$ represents correlation coefficient), its value is 1 , it shows the equation is highly linear correlated.

By Matlab calculated result, it is clear:

$$
\hat{y}=0.426+1.6447 x_{4}
$$

Among them, $y$ represents gender, $x_{4}$ represents probability of making friends and interaction. From formula (5), it is clear that probability of making friends and interaction is related to gender.

\subsection{Classification According to Age}

For Table 1 age type data, it does processing and gets Table $\mathbf{3}$ data, contents are as Table $\mathbf{3}$ shows. To convenient to make regression, transform percentage into decimals, 6064 years old people use "1" to express, 65-69 years old people use " 2 " to express, 70-74 years old people use " 3 " to express, 75-79 years old people use " 4 " to express, 80 years old and above such people use " 5 " to express.

For Table 3 contents, utilize Matlab to program above multiple linear regression models, by calculating, it gets following results.

$$
\begin{aligned}
\mathrm{b}= & (104.8714,-62.4181,-136.1791,-108.3835,0,-31.8631) \\
& \text { stats }=(1,72.8240,0.022)
\end{aligned}
$$

By consulting table, it is clear that R2 is on behalf of decision coefficient( $R$ represents correlation coefficient), its value is 1 , it shows the equation is highly linear correlated. 
Table 4. Cultural standards classification old people demands status table.

\begin{tabular}{|c|c|c|c|c|c|}
\hline Type & Pass Time & Relax & Capacity Improving & $\begin{array}{c}\text { Make Friends and } \\
\text { Interaction }\end{array}$ & Explore Knowledge \\
\hline \hline 1 & 0.2073 & 0.4268 & 0.2927 & 0.0610 & 0.0122 \\
\hline 2 & 0.1695 & 0.5085 & 0.2203 & 0.0678 & 0.0339 \\
\hline 3 & 0.1667 & 0.4167 & 0.2778 & 0.0556 & 0.0833 \\
\hline 4 & 0.00 & 0.3333 & 03333 & 0.3333 & 0.00 \\
\hline
\end{tabular}

Table 5. Monthly income classification old people demands status table.

\begin{tabular}{|c|c|c|c|c|c|}
\hline Type & Pass Time & Relax & Capacity Improving & $\begin{array}{c}\text { Make Friends and } \\
\text { Interaction }\end{array}$ & Explore Knowledge \\
\hline \hline 1 & 0.3871 & 0.2581 & 0.2903 & 0.0645 & 0.00 \\
\hline 2 & 0.1346 & 0.5577 & 0.2500 & 0.0385 & 0.0192 \\
\hline 3 & 0.1034 & 0.4483 & 0.3103 & 0.1034 & 0.0345 \\
\hline
\end{tabular}

By Matlab calculated result, it is clear:

$\hat{y}=104.8714-62.4181 x_{1}-136.1791 x_{2}$

$-108.3835 x_{3}-31.8631 x_{5}$

Among them, $y$ represents age type, $x_{1}$ represents pass time demand probability, $x_{2}$ represents relax demand probability, $x_{3}$ represents capacity improving demand probability, $x_{4}$ represents make friends and interaction demand probability. From formula (6), it is clear that explore knowledge demand is unrelated to age.

\subsection{Classification According to Cultural Standards}

For Table 1 cultural standards type data, it does processing and gets Table $\mathbf{4}$ data, contents are as Table $\mathbf{4}$ shows. To convenient to make regression, transform percentage into decimals, education background as junior high school and below is using "1" to express, education background as senior high school or technical secondary school is using " 2 " to express, education background as undergraduate course is using " 3 " to express, education background as master and above is using " 4 " to express.

For Table 4 contents, utilize Matlab to program above multiple linear regression models, by calculating, it gets following results.

$$
\begin{aligned}
& \mathrm{b}=(-1.571203 .2538013 .461329 .614) \\
& \text { stats }=(1,69.6220,0.0013)
\end{aligned}
$$

By consulting table, it is clear that $\mathrm{R} 2$ is on behalf of decision coefficient( $R$ represents correlation coefficient), its value is 1 , it shows the equation is highly linear correlated.

By Matlab calculated result, it is clear,

$$
\hat{y}=-1.5712+3.2538 x_{2}+13.4613 x_{4}+29.614 x_{5}
$$

Among them, $y$ represents cultural background type, $x_{2}$ represents relax demand probability, $x_{4}$ represents make friends and interaction demand probability, $x_{5}$ represent explore knowledge demand probability. From formula (7), it is clear that pass time and capacity improving demands are unrelated to cultural standards.

\subsection{Classification According to Monthly Income}

For Table 1 monthly income type data, it does processing and gets Table $\mathbf{5}$ data, contents are as Table $\mathbf{5}$ shows. To convenient to make regression, transform percentage into decimals, income that is less than 1000 Yuan is using " 1 " to express, income that is $2000-3000$ Yuan is using " 2 " to express, above 3000 Yuan is using " 3 " to express.

For Table 5 contents, utilize Matlab to program above multiple linear regression models, by calculating, it gets following results.

$$
\begin{aligned}
& \mathrm{b}=(6.8273,-11.0627,-5.9858,0,0,0) \\
& \text { stats }=(1,63.5420,0.0013)
\end{aligned}
$$

By consulting table, it is clear that R2 is on behalf of decision coefficient( $R$ represents correlation coefficient), its value is 1 , it shows the equation is highly linear correlated.

By Matlab calculated result, it is clear,

$\hat{y}=6.8273-11.0627 x_{1}-5.9858 x_{2}$

Among them, $y$ represents monthly income type, $x_{1}$ represents pass time demand probability, $x_{2}$ represents relax demand probability. From formula (8), it is clear that pass 
Table 6. Income satisfaction classification old people demands status table.

\begin{tabular}{|c|c|c|c|c|c|}
\hline Type & Pass Time & Relax & Capacity improving & $\begin{array}{c}\text { Make Friends and } \\
\text { Interaction }\end{array}$ & Explore Knowledge \\
\hline \hline 1 & 0.1333 & 0.4667 & 0.3333 & 0.0667 & 0.00 \\
\hline 2 & 0.1447 & 0.5132 & 0.2368 & 0.0789 & 0.0263 \\
\hline 3 & 0.2407 & 0.4259 & 0.2222 & 0.0870 & 0.0556 \\
\hline 4 & 0.2174 & 0.3478 & 0.3478 & 0.00 & 0.083 \\
\hline 5 & 0.1667 & 0.3333 & 0.3333 & \\
\hline
\end{tabular}

Table 7. Physical health status classification old people demands status table.

\begin{tabular}{|c|c|c|c|c|c|}
\hline Type & Pass Time & Relax & Capacity Improving & $\begin{array}{c}\text { Make Friends and } \\
\text { Interaction }\end{array}$ & Explore Knowledge \\
\hline \hline 1 & 0.2026 & 0.4872 & 0.4872 & 0.1026 & 0.0513 \\
\hline 2 & 0.1200 & 0.4800 & 0.4800 & 0.0533 & 0.0625 \\
\hline 3 & 0.2292 & 0.4167 & 0.2708 & 0.0588 & 0.0208 \\
\hline 4 & 0.4706 & 0.3529 & 0.1176 & 0.00 & 0.00 \\
\hline 5
\end{tabular}

time and relax demands are related to monthly income extent.

\subsection{Classification According to Income Satisfaction}

For Table 1 income satisfaction type data, it does processing and gets Table $\mathbf{6}$ data, contents are as Table $\mathbf{6}$ shows. To convenient to make regression, transform percentage into decimals, very satisfied with income is using " 1 " to express, satisfied with income is using " 2 " to express, general satisfaction with income is using " 3 " to express, dissatisfied with income is using "4" to express, very dissatisfied with income is using " 5 " to express.

For Table 6 contents, utilize Matlab to program above multiple linear regression models, by calculating, it gets following results.

$$
\begin{aligned}
& \mathrm{b}=(39.7432,-35.3581,-50.6063,-35.9495,23.5369,0) \\
& \text { stats }=(1,65.7570,0.0024)
\end{aligned}
$$

By consulting table, it is clear that $\mathrm{R} 2$ is on behalf of decision coefficient( $R$ represents correlation coefficient), its value is 1 , it shows the equation is highly linear correlated.

By Matlab calculated result, it is clear,

$y=39.7432-35.3581 x_{1}-50.6063 x_{2}-35.9495 x_{3}+23.5369 x_{4}(9)$

Among them, $y$ represents age type, $x_{1}$ represents pass time demand probability, $x_{2}$ represents relax demand probability, $x_{3}$ represents capacity improving demand probability, $x_{4}$ represents make friends and interaction demand probability. From formula (9), it is clear that explore knowledge demand is unrelated to income satisfaction.

\subsection{Classification According to Physical Health Status}

For Table 1 physical health status type data, it does processing and gets Table 7 data, contents are as Table 7 shows. To convenient to make regression, transform percentage into decimals, old people health status is very good that will use " 1 " to express, health status is good that will use " 2 " to express, health status is general that will use " 3 " to express, health status is poor that will use "4" to express, health status is very bad that will use " 5 " to express.

For Table 7 contents, utilize Matlab to program above multiple linear regression models, by calculating, it gets following results.

$$
\begin{aligned}
& \mathrm{b}=(5.000,0.5309,1.8780,-5.9761,-20.5750,0) \\
& \text { stats }=(1,64.6650,0.0019)
\end{aligned}
$$

By consulting table, it is clear that $\mathrm{R} 2$ is on behalf of decision coefficient ( $R$ represents correlation coefficient), its value is 1 , it shows the equation is highly linear correlated.

By Matlab calculated result, it is clear:

$\hat{y}=5.000+0.5309 x_{1}+1.8780 x_{2}-5.9761 x_{3}-20.5750 x_{4}(10)$

Among them, $y$ represents age type, $x_{1}$ represents pass time demand probability, $x_{2}$ represents relax demand 
probability, $x_{3}$ represents capacity improving demand probability, $x_{4}$ represents make friends and interaction demand probability. From formula (10), it is clear that explore knowledge demand is unrelated to physical health status.

\section{CONCLUSION}

Linear regression analysis is a mathematical tool that researches variables correlations; it can help us to use variable assigned value to estimate another variable assigned value. The model application field is very wide, such as talents demand problem, engineering technical problem and other aspects analysis problems. The paper applies multiple linear regression models into researching old people sports leisure demands problem, researches sports demands relationship with old people age, gender, cultural standards, monthly income and other aspects from multiple perspectives. Probability of making friends and interaction is related to gender. Demand of exploring knowledge is unrelated to age. Pass time and capacity improving demands are uncorrelated to cultural standards. Pass time and relax demands are related to monthly income extent. Demand of exploring knowledge is unrelated to income satisfaction. Demand of exploring knowledge is unrelated to physical health status. In future old people sports leisure demands problems researches, above conclusion will play important driving roles.

\section{CONFLICT OF INTEREST}

The author confirms that this article content has no conflict of interest.

\section{ACKNOWLEDGEMENTS}

Declared none.

\section{REFERENCES}

[1] C. Po, Q. Zhong-Mei, Y. Ying, and X. Chong-De, "Correlation analysis of current situation of regional athletics sports development and society population structure in China," J. Beijing. Sport. Univ., vol. 30, no. 12, pp. 1610-1613, 2007.

[2] G. Hong, "Summary on chinese sports population research since 1980s," China Sport Sci. Technol., vol. 43, no. 3, pp. 36-40, 2007.

[3] L. Hong, X. Hai-hong, and F. Wu-long, "Sociological analysis of comparison of chinese population with the sports population of chinese," J. Xi'an Inst. Phys. Educ., vol. 24, no. 4, pp. 25-28, 2007.

[4] M. Zhi-wen, and Q. Chun-lin, "Sociological analysis of contemporary Chinese sports population structures," J. Phys. Educ., vol. 13, no. 1, pp. 119-121, 2006.

[5] X. Huan-yu, and F. Li, "Concept, classification and statistical criteria of sports population," Sports Sci. Res., vol. 26, no. 1, pp. 7-10, 2005.

[6] X. Jin-xia, and W. Jing-tong, "Analysis on development level of competitive sports of eastern,"china in the "eleventh five-year" period," Bull. Sport Sci. Technol., vol. 19, no. 4, pp. 57-59, 2011.

[7] Y. De-yi, "Development of sports for all under circumstance of building well-off society," J. Wuhan Inst. Phys. Educ.,vol. 40, no. 1, pp. 15-19, 2006.

\footnotetext{
Received: June 10, 2015

(C) Ping Dai; Licensee Bentham Open.

This is an open access article licensed under the terms of the (https://creativecommons.org/licenses/by/4.0/legalcode), which permits unrestricted, noncommercial use, distribution and reproduction in any medium, provided the work is properly cited. 